\title{
Fuerza Armada en la Revolución Bolivariana de Venezuela (1999-2012)
}

\author{
Sánchez Medero, Gema*
}

\section{Resumen}

En este artículo se analiza el papel de la Fuerza Armada en la Revolución Bolivariana y la política de defensa que ha primado en Venezuela desde 1999 hasta 2012. Si por algo se ha caracterizado el proceso revolucionario bolivariano es por encontrase vinculado a la Fuerza Armada Nacional, un cuerpo que ha sufrido toda una transformación durante estos años, al igual que la política de defensa. Y es precisamente en este punto donde se centra esta investigación, fijar y evaluar los cambios que se han producido en ambas esferas para conocer su verdadero impacto en la revolución bolivariana. Para ello se analizarán la Constitución de 1999, la Ley Orgánica de Seguridad de la Nación (2002), la Ley Orgánica de la Fuerza Armada Nacional (2005), la Ley de Orgánica de Consejos Comunales, principalmente, además de la bibliografía existente sobre la materia. La Fuerza Armada se encuentra presente en todos los ámbitos, convirtiéndose, junto al pueblo, en el protagonista del proceso.

Palabras clave: Fuerza Armada, política de defensa, Hugo Chávez, Revolución Bolivariana.

\section{The Armed Forces in the Bolivarian Revolution in Venezuela (1999-2012)}

This article analyzes the role of the armed forces in the Bolivarian Revolution and the defense policy that has prevailed in Venezuela from 1999-2012. The Bolivarian revolutionary process can be characterized as being linked to the National Armed Forces, a body that has undergone a complete transformation during these years, along with the defense policy. The research focuses precisely on this point: to establish and evaluate the changes that have occurred in both areas in order to know their true impact on the Bolivarian revolution. To accomplish this, principally the 1999 Constitution, the Organic Law for National Security (2002), the Organic Law of the National Armed Forces (2005) and the Organic Law of Communal Councils will be analyzed, in addition to the existing literature on the subject. Results indicate that the armed forces are present in all ambits, becoming, together with the people, the protagonist of the process.

Keywords: Armed forces, defense policy, Hugo Chavez, Bolivarian Revolution.

\section{Recibido: 05-11-12 Aceptado: 27-04-14}

*** Doctora en Ciencias Políticas por la Universidad Complutense de Madrid, España. Profesora de Ciencia Política y de la Administración en la Universidad Complutense de Madrid, España.

E-mail: gsmedero@cps.ucm.es 


\section{Introducción}

La caracterización del llamado "proceso revolucionario bolivariano" en Venezuela se encuentra vinculado al papel que en el mismo ha desempeñado la Fuerza Armada Nacional. Tengamos en cuenta que, a raíz de la Constitución de 1999, la institución castrense divide su organización en dos, por un lado, existe una estructura tradicional equipada y adiestrada para la guerra convencional, y que, además, presta apoyo al Estado en el ámbito político, económico y social, y por otro, se configura toda una organización dedicada a la preparación de la guerra asimétrica, haciendo efectivo la corresponsabilidad entre el Estado y la Sociedad Civil. Así, se podría decir que los dos actores claves son el pueblo y la Fuerza Armada Nacional (FAN), por tanto, una estrecha relación entre ambos es fundamental para la defensa y el éxito de la revolución. Con lo cual, la FAN se ha convertido en el núcleo sobre el cual girará el proyecto político revolucionario, cosa que queda plasmada perfectamente en la Constitución de 1999. Por tal motivo, a lo largo de este artículo se va a analizar el rol de la FAN en la revolución bolivariana, y para ello, se determinará los cambios que se han producido en la misma respecto a etapas anteriores.

De esta manera, se podrá estudiar el papel que la FAN ha desempeñado en el proceso revolucionario, y su relevancia en el mismo. Al mismo tiempo, se analizará los cambios que se han producido en la política de defensa durante los gobiernos de Hugo Chávez con lo cual se podrá fijar los ejes sobre los que actualmente se mueve dicha política. Para ello, se ha rea- lizado una revisión documental del marco jurídico-político establecido en Venezuela a partir de 1999. En este sentido, se han analizado la Constitución de 1999, la Ley Orgánica de Seguridad de la Nación (2002), la Ley Orgánica de la Fuerza Armada Nacional (2005), la Ley de Orgánica de Consejos Comunales, entre otras; además de toda la documentación y bibliografía posible sobre la materia.

\section{La transformación de la Fuerza Armada en la Constitución de 1999}

En 1999 entra en vigencia la Constitución de la República Bolivariana de Venezuela que deroga la Constitución de 1961, y en virtud de ello, emergió una nueva referencia constitucional que de alguna forma reforzó el diseño institucional militar orientado a asuntos de orden interno y participación en el desarrollo integral de la nación. Además, con la entrada en funcionamiento de la Constitución de 1999 surgió la necesidad de realizar modificaciones legales a este respecto, entre las que cabe destacar la derogación de la Ley Orgánica de Seguridad Defensa de 1976, que fue sustituida por la Ley Orgánica de Seguridad de la Nación (LOSN, 2002), posteriormente se aprobaría la Ley Orgánica de la Fuerza Armada Nacional (LOFAN, 2005).

Así, los cambios constitucionales en cuanto al tema militar son importantes y van a determinar una nueva visión no solamente de las funciones y estructura de la FAN, sino también de la perspectiva sobre la seguridad nacional (Manrique, 2001).

Las modificaciones que se producen a raíz de esta nueva constitución son: 
- Las "Fuerzas Armadas Nacionales" pasan a denominarse "Fuerza Armanda Nacional" (FAN) para darle sentido de unidad y lograr una mejor ejecución de los fines que le han sido asignadas, como sucedía antes de 1958. En virtud de ello, se unifica a la FAN como un cuerpo militar uniforme integrado por los componentes: Ejército, Armada, Aviación y Guardia Nacional, que funcionarán de manera integral dentro del marco de sus competencias para el cumplimiento de su misión, pero preservando sus características, eso sí eliminando la autonomía de las fuerzas respectivas. A esto debe agregarse la creación de la Reserva Militar Nacional. Además, se fija, en el art. 328 que la FAN también cooperará en el mantenimiento del orden interno y que participará en el desarrollo nacional, lo que ha contribuido al incremento de la presencia militar en áreas civiles y, por lo tanto, en su creciente autonomía. El art. 329 señala, además, que "podrá ejercer actividades de policía administrativa y de investigación penal que le atribuya la ley". Asimismo se introduce la figura de antejuicio de mérito para los miembros de la FAN, para poder ser enjuiciados por el Tribunal Supremo de Justicia (TSJ), y se le otorga a la FAN el control sobre la comercialización, adquisición, fabricación, registro, entre otros, de armas y explosivos que anteriormente estaba en manos del Ministerio de Relaciones Interiores (Jácome, 2006).
- La Constitución fija que la estructura de la FAN es la siguiente (Asamblea Nacional, 1999):

a El Comandante en Jefe: El Presidente de la República Bolivariana de Venezuela pasa a tener el grado militar de Comandante en Jefe, y es la máxima autoridad jerárquica de la FAN (art. 6), (Asamblea Nacional, 2005). Por eso, tiene la facultad de dirigir el desarrollo general de las operaciones, definir y activar el área de conflicto; promover a sus oficiales a partir de grado coronel o capitanía de navío; dirigir la Comandancia en Jefe, integrada por un Estado mayor y las unidades que designe; y convocar y presidir el Consejo de la Defensa Nacional.

b Ministerio del Poder Popular para la Defensa: Es el máximo órgano administrativo en materia de defensa militar de la Nación, encargado de la formulación, adopción, seguimiento y evaluación de las políticas, estrategias, planes, programas y proyectos del Sector Defensa, sobre los cuales ejerce su rectoría de acuerdo con lo establecido en la Ley Orgánica de la Administración Pública (Asamblea Nacional, 2008).

c Alto Mando Militar: Según el artículo 42 de la LOFAN 2005, está integrado por el Ministro de la Defensa, el Jefe del Estado Mayor de la Defensa, el Inspector General, los Comandantes de los cuatro Componentes Militares, el Jefe del Comando Estratégico Operacional y el Jefe del Comando 
General de la Reserva Nacional y de la Movilización Nacional (art. 42, LOFAN, 2005) (Asamblea Nacional, 2005).

d El Consejo de Defensa de la Nación (CODENA) es el máximo órgano de consulta para la planificación y asesoramiento del Poder Público en los asuntos relacionados con la defensa integral de la Nación, su soberanía y la integridad de su espacio geográfico. A tales efectos, le corresponde también establecer el concepto estratégico de la Nación. Presidido por el Presidente o Presidenta de la República, lo conforman, además, el Vicepresidente Ejecutivo o Vicepresidenta Ejecutiva, el Presidente o Presidenta de la Asamblea Nacional, el Presidente o Presidenta del Tribunal Supremo de Justicia, el Presidente o Presidenta del Consejo Moral Republicano y los Ministros o Ministras de los sectores de la defensa, la seguridad interior, las relaciones exteriores y la planificación, y otros cuya participación se considere pertinente. Por otra parte, la Secretaría Ejecutiva del CODENA (SECODENA), bajo la dirección de un Secretario General, nombrado por el Presidente de la República, es un órgano de apoyo administrativo, técnico y de investigación. En su estructura se incluyen los Comités Coordinadores, un centro de evaluación estratégica, y otro de política y estrategia, aparte de la oficina administrativa. Entre sus funciones está el análisis de la información para la elaboración de planes y proyectos, el seguimiento y evaluación para la alerta temprana que se lleva a cabo en la Sala Situacional de la Presidencia de la República, y la elaboración de propuestas políticas y estratégicas para resolver problemas relacionados con la seguridad y la defensa. En todo caso, desde su creación se ha ocupado de formular los diferentes reglamentos de la Ley Orgánica de Seguridad de la Nación, tales como el Reglamento Especial sobre Zonas de Seguridad (enero de 2004) y el Reglamento del CODENA (mayo de 2004) (Jácome, 2007: 40).

e El Comando Estratégico Operacional es el máximo órgano de programación, planificación, dirección, ejecución y control estratégico operacional conjunto (art. 60, LOFAN), (Asamblea Nacional, 2005). Es parte integrante de la Junta Superior de la FAN. Su dirección está en manos del Estado Mayor Conjunto y depende directamente del Presidente de la República. El Comandante Estratégico Operacional se encuentra vinculado directamente al Presidente o Presidenta de la República Bolivariana de Venezuela, pero también lo está el Comandante en Jefe de la Fuerza Armada Nacional Bolivariana para todo lo relativo a los aspectos operacionales, mientras que para los asuntos administrativos dependerá del Ministro del Poder Popular para la Defensa (art. 20, LOFAN), (Asamblea Nacional, 2005).

f Reserva tiene la misión central de defensa de la soberanía, entre sus objetivos está el resguardo de los recursos petroleros del país. Además, la reserva tiene la misión de complementar a la FAN, participar en el de- 
sarrollo nacional y cooperar en el mantenimiento del orden interno.

g Guardia Territorial tiene la misión de "preparación y mantenimiento del pueblo organizado para operaciones de resistencia local ante cualquier agresión interna y/o externa, así como la participación en misiones especiales de defensa y desarrollo de la Nación" (art. 30. LOFAN), (Asamblea nacional, 2005). Este componente está integrado por los venezolanos que, sin haber prestado servicio militar, asumen en forma voluntaria el cumplimiento de las funciones de resistencia para lo cual serán entrenados y armados.

- A los militares se les reconoce su condición cívica y se les habilita parcialmente a participar en política a través del derecho al voto (art. 333. CRBV), (Asamblea Nacional, 1999) cosa que no sucedía anteriormente. Esta participación política, debe evitar la militancia. Aunque el texto constitucional vigente no restringe ni exime a la institución castrense a intervenir en otras facetas políticas, más allá de sus áreas operativas profesionales. Además, no existen restricciones ni limitaciones jurídicas al "dualismo democrático" que ejercen, actualmente, los oficiales venezolanos, quienes han sido libre- mente nombrados y removidos por el poder ejecutivo a lo largo y ancho de la estructura burocrática del Estado (Rodríguez, 2006: 264). Eso sí, se establece un mecanismo institucional para controlar las intenciones políticas del sector militar, es la potestad gubernamental de adjudicar los ascensos y los "pases a retiro" desde coroneles y capitanes de navíos, hasta generales y almirantes (Trinkunas, 2001) ${ }^{1}$. Anteriormente, la facultad institucional de los ascensos militares corría por cuenta de la Comisión de Defensa del Senado de la República. Lo cual, regularmente, suscitaba la participación y debate de los diversos representantes parlamentarios, incluyendo la oposición. Esta facultad es modificada en la Constitución de 1999, y se le confiere exclusivamente al Presidente de la República (Álvarez, 2004).

- Las funciones de las FAN se amplían considerablemente, pasan de seis a diecinueve. Entre las que cabe destacar, por novedosas: preparar y organizar al pueblo para la Defensa Integral; participar en alianzas o coaliciones con las Fuerzas Armadas de otros países para los fines de la integración dentro de las condiciones que se establezcan en los tratados; apoyar a los distintos niveles y ramas del Poder Público en la

En el Artículo 132 de la Constitución de 1961 establecía: "Las Fuerzas Armadas Nacionales forman una institución apolítica, obediente y no deliberante, organizada por el Estado para asegurar la defensa nacional, la estabilidad de las instituciones democráticas y el respeto a la Constitución y a las leyes, cuyo acatamiento estará siempre por encima de cualquier otra obligación. Las Fuerzas Armadas Nacionales estarán al servicio de la República, y en ningún caso al de una persona o parcialidad política" (Congreso nacional, 1961). 
ejecución de tareas vinculadas a los ámbitos social, político, cultural, geográfico, ambiental, económico y en operaciones de protección civil en situaciones de desastres en el marco de los planes correspondientes; contribuir en preservar o restituir el orden interno, frente a graves perturbaciones sociales, previa decisión del Presidente o Presidenta de la República Bolivariana de Venezuela y Comandante en Jefe de la Fuerza Armada Nacional Bolivariana; entre otros.

- Otra innovación importante que aporta la LOFAN (2005) es la reincorporación de militares retirados al servicio activo por decisión presidencial. Además, se fija una nueva línea de mando que se divide en dos: la conducción de operaciones militares -línea de mando operacional- y la conducción funcional o administrativa (Art. 15), (Asamblea Nacional, 2005). La primera, la ejecuta directamente el Presidente de la República o a través de un militar designado por éste, mientras que la segunda también la ejerce el Presidente pero a través del Ministro de la Defensa.

\section{Dimensión de la seguridad en Venezuela: la defensa y desarrollo integral}

En Venezuela la seguridad de la nación es considerada como la condición, estado o situación que garantice el goce y el ejercicio de los derechos y garantías en los ámbitos económicos, social, político, cultural, geográfico, ambiental y militar de los principios y valores constitucionales de la población, institu- ciones y en general a toda la sociedad (art. 02, LOSN), (Asamblea Nacional, 2002). Asimismo, la Constitución Nacional (1999) señala en su artículo 322 que "la seguridad de la nación es competencia esencial y responsabilidad del Estado, fundamentada en el desarrollo integral de ésta, y su defensa es responsabilidad de todos los venezolanos y venezolanas; también de las personas naturales y jurídicas, tanto de derecho público como de derecho privado, que se encuentren en el espacio geográfico nacional" (Asamblea Nacional, 1999).

Por tanto, la seguridad nacional de Venezuela se fundamenta principalmente en dos cuestiones, el desarrollo integral y la corresponsabilidad entre el Estado y sociedad civil, condiciones que promueven el goce y ejercicio de los derechos y garantías en los ámbitos económicos, social, político, cultural, geográfico, ambiental y militar (ver diagrama 1), correspondiéndole a la Fuerza Armada Nacional como expresión militar del poder nacional en Venezuela, garantizar la independencia, soberanía nacional y el respeto a los principios y valores expresados en el texto constitucional como son el establecimiento de una sociedad democrática, participativa y protagónica, multiétnica y pluricultural, que consolide la libertad, la independencia, la solidaridad, el bien común, la integridad territorial, la convivencia, el imperio de la ley y el mantenimiento de la paz.

En este sentido, deben fomentar, impulsar y defender el desarrollo integral de la nación, que consiste en ejecutar los planes, programas, proyectos y procesos continuos de actividades y labores acor- 
des, con la política general del Estado y en concordancia con el orden jurídico vigente, para conseguir satisfacer las necesidades individuales y colectivas de la población en todos los ámbitos. Además, como indica la Constitución, (1999) en su artículo 5 (LOFAN, 2005): "La Fuerza Armada Nacional participará en los procesos de integración de los pueblos latinoamericanos y caribeños, conforme a los tratados y convenios que suscriba la República, y podrá emprender acciones combinadas en defensa de los procesos orientados a la constitución de una comunidad de naciones que recoja ese legado histórico" (Asamblea nacional, 1999-2005) (Diagrama 1).

Por tanto, la Fuerza Armada Nacional es una parte esencial e indisoluble del Poder Público Nacional, basado éste en los intereses y objetivos nacionales establecidos para el cumplimiento de las políticas correspondientes a la defensa militar, la cooperación en el mantenimiento del orden interno y la participación activa en el desarrollo integral del país, y que da origen al concepto estratégico militar con la finalidad de proporcionar la dirección estratégica para el funcionamiento y el desarrollo de la institución. Así, la incorporación de la Fuerza Armada Nacional al nuevo desarrollo económico, social, político, territorial e internacional, queda expresado en el "Plan Nacional de Desarrollo Económico y Social 2001-2007" (Ministerio del Poder Popular para la Planificación, 2000). Esto tiene gran importancia en el contexto de la fortaleza nacional, pues con ello se logra la mayor efectividad en la utilización de recursos humanos, materiales, financieros y tecnológi$c o s$, en virtud de la cual se requiere la modernización permanente de la institución, para asumir sus funciones militares específicas y de apoyo a otros organismos del Estado y la sociedad civil. De esta manera, la FAN sin olvidar su misión prioritaria, elaborará y ejecutará los planes dirigidos

\section{Diagrama 1 \\ Seguridad Nacional del Estado en Venezuela}

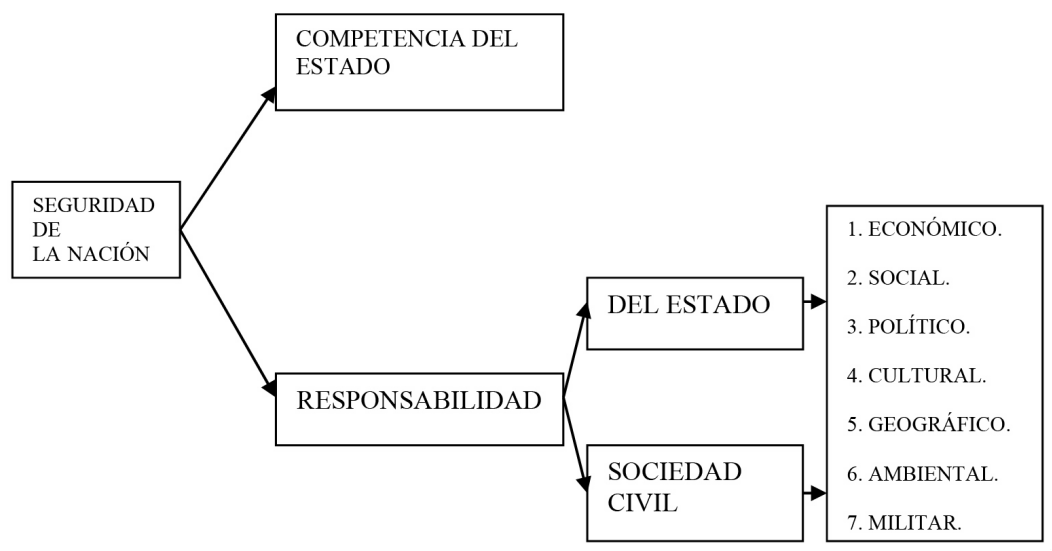

Fuente: Elaboración propia. 
a la cooperación en el Mantenimiento del Orden Interno ${ }^{2}$ y la Participación Activa en el Desarrollo Integral de la Nación, en concurrencia con el Plan Nacional de Desarrollo, el Plan Operativo Anual Nacional, los Planes Nacionales de Desarrollo Sectorial, el Plan Nacional de Desarrollo Institucional, y los demás planes que se establezcan (art. 7. b), (Asamblea Nacional, 2005) $)^{3}$.

Así, se podrá decir que en Venezuela la defensa de la nación, la seguridad y el orden interno implica algo más que el ámbito exclusivo del conflicto béli$\mathrm{co}$, ya que el concepto de seguridad asociado al desarrollo está vinculado a la promoción y la garantía de los derechos de los ciudadanos. Por tanto, hay más actores implicados en estas funciones que en otros países. Según indica la LOSN (2002), (Asamblea Nacional, 2002): a) En materia de seguridad y defensa, el Estado y la sociedad son corresponsables (art. 5), mientras que el Consejo de Defensa de la Nación (CODENA) es el "máximo órgano de consulta para la planificación y asesoramiento del Poder nacional, estatal y municipal, en los asuntos relacionados con la seguridad y la defensa in- tegral de la nación..." (art. 34); b) En lo relativo a la evaluación de los planes y programas de seguridad, defensa y desarrollo integral de la nación pueden participar los pueblos indígenas (art. 11); c) En lo concierte a la seguridad, desarrollo y defensa de los poderes públicos tienen competencias y se les obliga a definir y administrar políticas integrales de actuación (art. 16); d) En el orden interno es el Estado quien lo garantice (art. 18); y en ese sentido: los órganos de seguridad ciudadana civiles participan en la atención de emergencias y desastres, además de trabajar coordinadamente para preservar el orden interno (art. 23), mientras que la Fuerza Armada Nacional constituye uno de los elementos fundamentales para la defensa integral de la nación, organizada por el Estado para conducir su defensa militar en corresponsabilidad con la sociedad (art. 20). Con lo cual, no cabe duda que la visión general del sistema de defensa integral de la nación tiene un enfoque pluralista al nivel actoral y no está, como se puede comprobar, exclusivamente centrado en la FAN, es decir, los cambios jurídicos descritos incorporan además una serie de institu-

2 Además, para el mantenimiento del orden interno cooperará con la Policía Administrativa General y Especial en las funciones que les sean asignadas, como, por ejemplo (CEMFAN): -Ámbito político: no lo expresa;- Ámbito ambiental: Guardería del Ambiente y de los Recursos Naturales; - Ámbito social: Antidrogas, Seguridad y Orden público, colaborar en el mantenimiento de la vida socio-económica de la nación; - Ámbito cultural: consolidar el vínculo cívico-militar para lograr exaltar y fortalecer la identidad nacional con el objeto de fomentar el espíritu de unión entre la base del respeto mutuo y el principio de corresponsabilidad del Estado, y la sociedad en los ámbitos económicos, social y ambiental;--Ámbito económico: Resguardo Nacional, control y funcionamiento de los servicios públicos y de las industrias básicas de importancia estratégica para el Estado; - Ámbito militar: Guardacostas, Seguridad Fronteriza, operaciones especiales de Seguridad Interna.

3 Concepto Estratégico de Defensa Integral de la Nación (CEDIN, 2002). 
ciones y redes de actores que inciden significativamente en esos elementos. Se trata pues, de un proceso dinámico en el que interactúan actores y se relacionan conceptos apoyándose mutuamente en una acción de sinergía.

En cualquier caso, la política general del Estado venezolano que orienta la participación de la FAN en el desarrollo integral, se despliega en los siguientes lineamientos:

- La FAN acorde con sus capacidades, limitaciones y cobertura geográfica de sus unidades operativas y administrativas, programarán su actuación según estrategias nacionales y directivas de planificación militar, basada en la doctrina de acción conjunta, en la descentralización financiera y ejecución descentralizada, sin abandonar sus funciones relacionadas con la defensa militar.

- La planificación y ejecución de las actividades militares en apoyo al desarrollo del país debe hacerse en sentido nacional, en plena cooperación con los Consejos de Planificación y Coordinación de Políticas Públicas Nacionales, Estadales y Municipales, con la finalidad de satisfacer las necesidades individuales y colectivas de la población en todos los ámbitos.

- En apoyo a la seguridad alimentaria, se activará una entidad rectora dentro de la institución castrense, en estrecha coordinación con otros organismos del sector público y el sector privado, para dirigir la distribución de alimentos y mercados populares.

- En apoyo a las infraestructuras del país, se encarga de dirigir los organis- mos encargados de construir carreteras y viviendas populares.

- Para la integración entre la estructura militar potencialmente productiva y los centros de producción del país se promoverán alianzas estratégicas con miras al desarrollo y consolidación de la Industria Militar, Naval y Aeroespacial con el aporte de fondos y capital humano del sector público y privado.

- La participación en el desarrollo del binomio Fuerza Armada Nacional y sociedad civil, se hará a través del desarrollo de proyectos y programas de apoyo a la comunidad y protección del ambiente. Así, en el Fuerte Tiuna, por ejemplo, funcionan oficinas públicas que atienden las demandas de los ciudadanos para ser beneficiarios de las denominadas "misiones". Además, la FAN ha participado directamente en las siguientes misiones:

- Misiones Robinson I y Robinson II: Es un plan de alfabetización que consiste en una operación cívico-militar para enseñar a leer y a escribir a más de un millón de venezolanos distribuidos por todo el territorio nacional.

- Plan Bolívar 2000: La FAN ayudó en la activación de unidades especiales reservistas, y además contribuyó a la puesta en marcha de tres de su subplanes: el Plan de Empleo Simón Rodríguez, la Operación Avispa y el Plan Bolívar 2001.

- Misión MERCAL: Tiene como objeto efectuar el mercadeo y comercialización permanente de productos alimenticios. La FAN ha participado en esta misión comercializando productos alimenticios y otros de primera necesi- 
dad, en la modalidad de cielos abiertos, cuando así lo ordena el gobierno.

- Misión Miranda: Su función es organizar, captar, registrar, controlar y reestrenar la Reserva de la FAN.

- El Sistema Educativo Militar formará, capacitará y adiestrará a profesionales que estén comprometidos con la defensa integral y la participación activa en el desarrollo del país, logrando una formación integral.

\section{Dimensión de la seguridad en Venezuela: el concepto y estrategia de la guerra asimétrica.}

El Presidente Hugo Chávez apuesta por el conflicto asimétrico por ser el modelo más apropiado para que Venezuela pueda hacer frente a sus desafíos y amenazas militares. No obstante, es la metodología del débil contra el fuerte, es decir, de David contra Goliat. Ya que la característica primordial de esta estrategia es el uso de la disparidad entre las partes contendientes para sacar ventaja, de ahí que la asimetría sea definida como "actuar, organizar y pensar de forma diferente que los oponentes con el fin de maximizar las ventajas propias, explotar las debilidades del oponente, obtener la iniciativa o ganar mayor libertad de acción. Puede tener dimensiones psicológicas y físicas" (Metz y Johnson, 2001: 5-6). Por tanto, el con- cepto de conflicto asimétrico de Chávez, implica una especie de "superinsurgencia" que integre los instrumentos fundamentales del poder político, económico, social-moral, de información y militar, y cuyo objetivo sea intentar resistir, oponer, controlar, o derrocar a un gobierno y crear un cambio político fundamental (Manwaring, 2006). Esta creencia está fundamentada en la idea de una guerra revolucionaria asimétrica, que va más allá de la confrontación entre Estados soberanos, con estrategias y tácticas diferentes, en donde a la superioridad técnica que tiene el "imperialismo" se le responde con flexibilidad táctica, sin un campo de batalla establecido y conocido y con el apoyo de la población civil en armas. De ahí, que en el Foro sobre Guerra de Cuarta Generación y Guerra Asimétrica, llevado a cabo en Caracas a principios de 2004, el Presidente ordenará que la FAN desarrollase una nueva doctrina militar, la guerra asimétrica.

Pero la teoría de la "guerra asimétrica" y los fundamentos doctrinales que justifican la creación de la "milicia", no tiene precedentes en la historia militar venezolana. En todo caso, con la instauración de la "Milicia Nacional Bolivariana" se fortalece el concepto de corresponsabilidad cívico-militar en la defensa, al hacer partícipe a la sociedad civil de la defensa nacional en apoyo al ejército regular ${ }^{4}$. Por lo cual, se modifica la doctrina militar impeque no estén en servicio militar activo, que hayan cumplido con el servicio militar o que voluntariamente se incorporen a las unidades de reservas que al efecto sean conformadas (art.10, LOFAN), (Asamblea Nacional, 2002). 
rante hasta 1999, en función de la defensa integral, para cuyos efectos se requiere una organización de tipo cívica-militar en tres niveles: 1) Fuerza Armada Nacional, 2) Reserva Militar, y 3) Guardia Territorial. Así, los dos actores principales en la puesta marcha de un gobierno de carácter cívico-militar son el pueblo y la FAN, es más ésta última será el núcleo alrededor del cual girará el proyecto político revolucionario. Aunque para algunos analistas, este nuevo pensamiento genera problemas, ya que está provocando un distanciamiento del control civil sobre lo militar, lo que conduce a una militarización de la seguridad (Ramos y Otálvaro, 2004, 38).

En cualquier caso, habría que señalar a este respecto que son los Consejos Comunales ${ }^{5}$ el centro principal de la participación y protagonismo del pueblo en la formulación de ideas, propuestas y proyectos que se puedan traducir y ejecutar como políticas públicas. Por eso, sería necesario determinar, antes de nada, cuál es el rol de los Consejos Comunales en los temas relacionados con la seguridad y la defensa. Así, por ejemplo, habría que señalar que "la Asamblea de Ciudadanos y Ciudadanas determina y elige el número de voceros o voceras de acuerdo a la cantidad de comités de trabajo que se conformen en la comunidad, tales como: Numeral 8. Comité de Seguridad Inte- gral...." (art. 9, LECC), (Asamblea Nacional, 2009).

Además, "el Consejo Comunal a través de su órgano ejecutivo tendrá las siguientes funciones: articular con las organizaciones sociales presentes en la comunidad y promover la creación de nuevas organizaciones donde sea necesario, en defensa del interés colectivo y el desarrollo integral, sostenible y sustentable de la comunidad (art. 21.2, LECC); organizar el voluntariado social en cada uno de los Comités de Trabajo (art. 21.4, LECC); organizar el Sistema de Información Comunitaria Numeral (art. 21.6, LECC); promover el ejercicio y defensa de la soberanía e integridad territorial de la nación (art. 21.9, LECC). De tal manera, la Ley de los Consejos Comunales refuerza todavía más si cabe ese vínculo esencial entre la población y el gobierno, ya delineado tanto en la Constitución Nacional (art. 326), (Asamblea Nacional, 1999) como en la Ley Orgánica de Seguridad de la Nación (art. 5), (Asamblea Nacional, 2002) en lo relativo a la seguridad y defensa integral, sobre la base del principio de la corresponsabilidad. Tal es así, que los Consejos Comunales incluso pueden, agrupados en un Comité de Seguridad Integral, atender a los problemas de seguridad que se produzcan en un espacio geográfico cercano. Con esto no se quiere decir que el Consejo Comunal asuma el rol de

Los Consejos Comunales son instancias de participación, articulación e integración entre las diversas organizaciones comunitarias, grupos sociales y los ciudadanos y ciudadanas, que permitan al pueblo organizado ejercer directamente la gestión de las políticas públicas y proyectos orientados a responder a las necesidades y aspiraciones de las comunidades en la construcción de una sociedad de equidad y justicia social”. Art. 2, Ley Especial de los Consejos Comunales (LECC), (Asamblea Nacional, 2009). 
los cuerpos de seguridad del Estado, sino más bien que a través de la denuncia y el suministro oportuno de información facilitan la labor de las autoridades competentes para resolver el conflicto.

Aunque está lógica de procedimiento también puede emplearse para situaciones de mayor alcance relacionadas con la seguridad y la defensa. Para ello, el Comité de Seguridad Integral, tendría que recurrir a la Guardia Territorial, además, los Consejos Comunales ante un hipotético conflicto externo, podrían asumir operaciones de defensa asimétrica pero también podrían actuar como una fuente importante de información, realizándose así plenamente el concepto de la corresponsabilidad entre el Estado y la sociedad civil.

Sin embargo, hay un hecho que se debe tener en cuenta a este respecto, cabe recordar que entre las funciones de la milicia se encuentran algunas que interfieren directamente en los Consejos Comunales. Por ejemplo, la milicia tiene que "orientar, coordinar y apoyar en las áreas de su competencia a los Consejos Comunales, a fin de coadyuvar en el cumplimiento de las políticas públicas"; "contribuir y asesorar en la conformación y consolidación de los Comités de Defensa Integral de los Consejos Comunales, a fin de fortalecer la unidad cívico-militar"; "recabar, procesar y difundir la información de los Consejos Comunales, instituciones del sector público y privado, necesaria para la elaboración de los planes, pro- gramas, proyectos de Desarrollo Integral de la Nación y Movilización Nacional" (art. 46, LOFAN), (Asamblea Nacional, 2005).

Por otra parte, Venezuela ha fortalecido el concepto de corresponsabilidad cívico-militar en la defensa, con la creación de la Milicia Nacional Bolivariana, que posibilita la organización y el entrenamiento de la población para apoyar a las tropas regulares. Ya que su misión es entrenar, preparar y organizar al pueblo para la defensa integral con el fin de complementar el nivel de apresto operacional de la FAN, contribuir al mantenimiento del orden interno, seguridad, defensa y desarrollo integral de la Nación, con el propósito de coadyuvar a la independencia, soberanía e integridad del espacio geográfico de la Nación (art. 44, LOFAN) ${ }^{6}$. Así, la misión del Comando General de la Milicia es constituirse en una organización moderna, dinámica, integrada por el recurso popular nacional, que le permita al Estado maximizar el apresto operacional de la FAN, mediante la incorporación de las unidades de la Reserva para coadyuvar en la defensa de la soberanía y en la integridad del territorio de la nación, mantenimiento el orden interno y la participación activa en el desarrollo nacional. Por tanto, la milicia es un cuerpo especial integrado por la Reserva Nacional y la Guardia Territorial, y que depende para asuntos operativos del Presidente de la República Bolivariana de Venezuela y para los administrativos del Ministerio de Defensa. Además, con la nueva reforma de la Ley 
Orgánica de la Fuerza Armada Nacional del 21/10 la milicia también crea y organiza los "Cuerpos Combatientes", que son unidades conformadas por ciudadanos y ciudadanas que trabajan en las instituciones públicas o privadas, que de manera voluntaria son registrados o registradas, organizados $u$ organizadas y adiestrados o adiestradas por el Comando General de la Milicia Bolivariana en la defensa integral de la Nación, asegurando la integridad y operatividad de las instituciones a las que pertenecen" (art. 50, LOFAN), (Asamblea Nacional, 2005). Con este artículo se da un salto en el control sobre el movimiento obrero en general, favoreciendo a sectores de trabajadores a organizarse.

La Reserva Militar Nacional se ha convertido en la responsable de complementar la Fuerza Armada Nacional activa para dar cumplimiento a sus funciones, $y$ proporcionarles reemplazos a sus unidades, además de cualquier otra que se le asigne para la defensa integral de la Nación. La Reserva Militar Nacional la conforman todos los ciudadanos venezolanos mayores de edad que no estén en servicio militar activo, que hayan cumplido con el servicio militar o que voluntariamente se incorporen a las unidades de reservas. Es un cuerpo especial que cuenta con una Comandancia General de la Reserva Nacional y de la Movilización Nacional y los órganos operativos y administrativos funcionales necesarios para el cumplimiento de su misión.

Los componentes militares de esta organización están bajo las órdenes de su respectivo Comandante General quien ejerce el mando, dependiendo del Ministro de la Defensa en la administración, organización, adiestramiento, dotación, apresto operacional, funcionamiento $y$ ejecución de los recursos asignados (art. 12, LOFAN), (Asamblea Nacional, 2005). Mientras que el Comandante de la Reserva Nacional y de la Movilización Nacional depende directamente del Presidente de la República Bolivariana de Venezuela, y tiene bajo su mando las unidades de reserva organizada y la Guardia Territorial organizada. Además, nombra a los Jefes de Guarnición de la Reserva, previa aprobación del Presidente de la República, y asiste a las reuniones del Estado Mayor Conjunto y del Comando Unificado de la FAN con voz pero sin voto.

En cualquier caso, la Reserva Militar Nacional está compuesta por: 1) Reservistas en situación activa: ciudadanos que ya cumplieron con el servicio militar, y que son llamados a reentrenamiento y actividades propiamente militares, y que acuden voluntariamente, es decir, son los denominados "soldados ciudadanos"; 2) Tropas alistadas en situación de excedencia: ciudadanos que cumplen el servicio militar por períodos especiales; 3 ) Ciudadanos: personas que sin haber cumplido el servicio militar se incorporan voluntariamente a recibir entrenamiento militar básico para prepararse, organizarse y participar en la defensa integral del país. Entre sus funciones se encuentran: consolidar el nuevo pensamiento militar, aumentar la preparación y eficacia de la FAN; participar en el trabajo social del gobierno; forta- 
lecer la unidad cívico-militar; y educar a la población en los principios militares.

Otra rama de la milicia, es la "Guardia Territorial", que tiene como misión la preparación y mantenimiento del pueblo organizado para operaciones de resistencia local, ante cualquier agresión interna y/o externa, así como la participación en misiones especiales de defensa y desarrollo integral de la Nación (art. 30, LOFAN), (Asamblea Nacional, 2005). La Guardia Territorial está constituida por los ciudadanos y ciudadanas que voluntariamente se organicen para cumplir funciones de resistencia local ante cualquier agresión interna o invasión de fuerzas extranjeras. Estos grupos deben ser debidamente registrados por la Comandancia General de la Reserva Nacional y de la Movilización Nacional, quedando bajo su mando y conducción (art. 11, LOFAN), (Asamblea Nacional, 2005) (Diagrama 2).

\section{Diagrama 2 Organización de la Reserva Nacional}

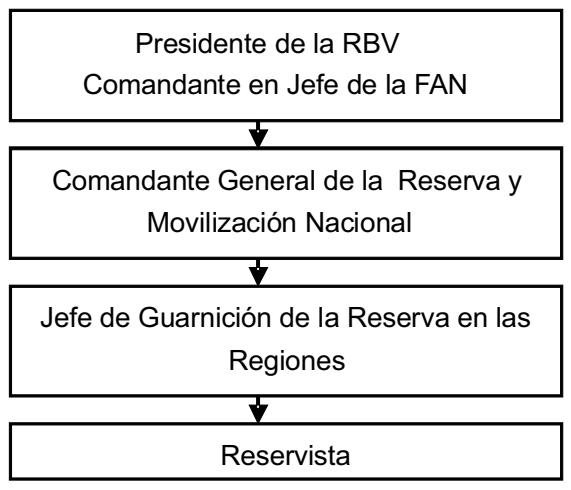

Fuente: Elaboración propia.

\section{La seguridad en Venezuela: la estrategia de su política exterior}

En el plano exterior, el proyecto de Hugo Chávez busca que Venezuela posea un alto perfil internacional a una escala mucho mayor que la que ha obtenido en décadas anteriores (Ramos y Otálvaro, 2004: 41). Es cierto, que en la nueva legislación venezolana no se contempla la posibilidad de que su Fuerza Armada no realice operaciones en el exterior, lo que tampoco quiere decir que lo no previsto se halle expresamente prohibido (Fernández, 2003: 178).

Sin embargo, se apuestan por otras fórmulas para hacerse presente en el ámbito exterior, como es la utilización del petróleo como principal instrumento para la participación en el escenario mundial y hemisférico; el activismo internacional del país; la promoción de un nuevo modelo político: la democracia participativa y protagónica; el lanzamiento de un nuevo modelo económico: el desarrollo endógeno y el socialismo del siglo XXI; la promulgación de una nueva Ley de Servicio Exterior; la ideologización del servicio exterior y la generación de una diplomacia "social" con el respaldo a diversas organizaciones políticas, sociales y culturales anti-globales en el ámbito internacional (Romero, 2007, 12).

Para poder hacer frente a la que consideran su amenaza externa más grave para el país, que según declara el propio Hugo Chávez, es la intención del gobierno de EE.UU por derrocar al gobierno 
venezolano (Brewer-Carías, 2007: 42) ${ }^{7}$. La estrategia se basa en la creación de un ejército popular para repeler al invasor, la confrontación abierta y constante con los EE.UU, la utilización del crudo como arma política y la concreción de alianzas estratégicas y comerciales con otros países. A este respecto se buscan alianzas extracontinentales con otros países como Rusia, Irán, China, India, Malí, España, Sudán, Kuwait y Corea del Norte (Jácome, 2007: 92). En el hemisferio se privilegian las relaciones con Cuba, los países del Cono Sur, especialmente Brasil, Argentina y Uruguay, y en la región andina con Bolivia después del cambio de gobierno en 2006 (Jácome, 2007: 92).

Por tal motivo, por ejemplo, Venezuela está intentado un acercamiento a países como China y Rusia, y para ello, se desarrollan intereses comunes tanto en los campos de la diplomacia multilateral y en el comercial como en el militar y en el tecnológico. Con la India también se están estableciendo lazos comerciales e ideológicos importantes, y con Irán se está consolidando un fuerte vínculo en materia militar-político, tecnología y comercial (Brewer-Carías, 2007: 43).

En cuanto a Cuba, se ha generado una relación especialmente favorable entre los dos países. Tal es así, que el presidente Chávez ha manifestado la necesidad de levantar el bloqueo de Estados Unidos a Cuba y ha reiterado en varias ocasiones su posición contraria a la tesis estadounidense de que no hay democracia interna en la isla (Romero, 2006: 43). De igual forma, se está incrementado el nivel de cooperación económica, ideológica y política entre ambos gobiernos y entre sectores políticos de ambas sociedades, para luego proyectar una transición política en la isla. Con Bolivia, incluso se ha suscrito el "Acuerdo de Cooperación Técnica entre la República de Bolivia y la República Bolivariana de Venezuela en materia de Defensa", que incluye la construcción de 24 bases militares (Romero, 2006:43).

En el ámbito geopolítico, se incluyen dos aspectos fundamentales: 1) La política de fronteras que está centrada en el desarrollo territorial a través de la desconcentración y la creación de tres fachadas: la Amazónica-Guayanesa, la Andina-Llanera y la Atlántico-Caribeña, y 2) El multilateralismo (Jácome, 2006: 45). Respecto al primer aspecto, se establece una política de repoblamiento que busca el apoyo para el desarrollo de proyectos agroindustriales que garanticen la supervivencia.

Esta política se complementa con la Ley de Reforma Agraria que apuesta al traspaso de las tierras improductivas a los campesinos dispuestos a llevar a cabo actividades agrícolas con ellas, por tanto, es una manera de seguir repoblando estas zonas. También propone una estrategia de descentralización que bus-

7 No obstante, el Gral. Müller Rojas declaró que existían pocas posibilidades de una invasión por parte de Estados Unidos pero que el país debía estar preparado para que eventualmente, con un cambio de condiciones bien sea externas o internas, esta potencia tome la decisión de seguir esa estrategia (Villegas, 2006: 24-25). 
ca aumentar las competencias de los debilitados municipios periféricos, para que éstos puedan dar respuesta a las preocupaciones de su población, y una política de intercambio comercial para revitalizar las zonas fronterizas (Asamblea Nacional, 2001).

Además, el Estado está presentado cuidado y apoyo especial a los pueblos indígenas que residen en los territorios marginados de Venezuela. Pero a la vez, recobra importancia el control del territorio y la seguridad. Respecto al segundo aspecto, han surgido nuevas iniciativas que desafían la hegemonía de EE.UU en el continente, la creación de la Comunidad Sudamericana de Naciones (CSN), o la "Alternativa Bolivariana para las Américas" (ALBA), una iniciativa de Hugo Chávez, para fomentar la integración política, económica y cultural, exclusivamente latinoamericana, frente al Área de Libre Comercio para las Américas $(A L C A)^{8}$. A ella se integró inmediatamente Cuba, después lo haría Bolivia y Nicaragua, y actualmente la componen nueve países: adicional a los mencionados están: Dominica, Honduras, Ecuador, San Vicente y las Granadinas, Antigua y Barbuda. La idea central es que al ALBA se adscriban todos los países de América Latina y el Caribe para crear una zona de libre comercio cuyos lazos se anudarán entre los países miembros, manteniendo muy poca relación con el mercado mundial, salvo para la comer- cialización del petróleo y el gas, y revitalizando MERCOSUR.

Por otra parte, el petróleo se convierte en un elemento esencial para la integración de América Latina y el Caribe. Más del $80 \%$ de las reservas de petróleo y gas del continente americano se encuentran en Latinoamérica, y por tal razón dentro de los objetivos estratégicos del Presidente está el propósito de garantizar la independencia energética de la región mediante Petroamérica (Brewer-Carías, 2007: 45). El objetivo de está organización es una alianza que busca la integración de las empresas estatales energéticas de America Latina, y para realizar inversiones conjuntas en áreas de exploración, explotación y refinación petrolera (Brewer-Carías, 2007: 45).

Argentina, Venezuela, Bolivia y Brasil han comprendido que es una "necesidad económica" hacer fuerza conjunta y sentar las bases para una verdadera integración regional que trascienda acuerdos comerciales. No obstante, la energía petrolera es un instrumento para la construcción de esquemas de unificación política. De este proyecto confluyen, además, tres iniciativas subregionales que son Petrosur, donde se agrupan Argentina, Brasil, Venezuela y Uruguay; Petrocaribe, cuyo nacimiento fue suscrito por 14 países de la región caribeña, y Petroandina, propuesta a los países que conforman la Comunidad Andina de Naciones (Bolivia, Ecuador, Colombia, Perú y Venezuela). 
Petroamérica tendría como base un acuerdo de integración enmarcado en un esquema más amplio (el ALBA); mientras que en Petrosur predominaría la complementariedad, cuya base doctrinal es el uso equilibrado de los recursos en el desarrollo de los pueblos; en Petrocaribe la cooperación energética está destinada a brindar facilidades financieras y garantizar el suministro directo hacia los países del área, con el fin de reducir la intermediación en el mercado de hidrocarburos; y en Petroandina, la alianza estratégica entre entes estatales. Además, en el 2006 se retira de la Comunidad Andina de Naciones, donde se encontraba Colombia y Perú, y del Grupo de los Tres (G3), conformado además de por Venezuela también por México y Colombia.

Otro elemento importante en la integración latinoamericana es Telesur, un canal de televisión impulsado por Chávez para fortalecer la autonomía informativa de esta parte del continente, y lograr una amplia cobertura internacional. Este canal tiene como principal socio inversionista a Venezuela (51\%), seguido por Argentina (20\%), Cuba (19\%) y Uruguay $(10 \%)$. Y todo porque una de las batallas más importantes contra la lucha contra el imperialismo estadounidense se libra en el campo de las telecomunicaciones, dado que el manejo y la propagación de la información a escala mundial son definitivos a la hora de ganar simpatizantes para la revolución (Ramos y Otálvaro, 2004).

En la esfera meramente militar, la Fuerza Armada venezolana está asumiendo como factible el posible conflicto con EE.UU, de lo que se desprende la re- orientación de las políticas de adquisición de armamento hacia Rusia, España, Brasil y China, entre otros. Así, durante la primera mitad de 2005, Venezuela firma cuatro importantes contratos para la compra de armamento, mediante los cuales adquiría a Brasil, por ejemplo, 12 o 14 aviones ligeros de ataque Super Tucano brasileños y 15 helicópteros; a España, 12 aeronaves C-295, 10 de transporte y 2 de vigilancia, 4 buques patrulleros, 4 corbetas y varios cargueros; a Rusia, 100.000 fusiles de asalto AK-103/AK-194 de 7,62 mm y la licencia para la fabricación de fusiles adicionales, entre otros. Por todo ello, el 15 de mayo de 2006, EEUU incluyó a Venezuela en la lista de países que no cooperan con EEUU en la lucha contra el terrorismo (Malamud, 2006).

Como consecuencia de esta situación, se suspende la venta y transferencia de armamento de EEUU a Caracas, así como el traspaso de armamento norteamericano, ya en manos de Venezuela a otros países; a China, 3 radares móviles tridimensionales de largo alcance JYL-1 (E/F Band) y personal para estudiar la fabricación y manejo de los satélites de comunicación (Malamud, 2006). La diversificación de compras de armas a otros países tiene la finalidad de poner fin a la dependencia respecto a EE.UU en este sentido. Al mismo tiempo, durante ese año se propone una unión militar continental sin la presencia de Estados Unidos, la Organización del Atlántico Sur (OTAS) como contraparte de la Organización del Atlántico Norte (OTAN), el problema es que apenas se está avanzando en esta propuesta. 


\section{Conclusiones}

Desde la llegada de Hugo Chávez al poder en 1999, el gobierno ha tenido un carácter meramente cívico-militar, donde el pueblo y la FAN son los actores principales. La definición del nuevo rol de estos actores aparece recogida en la Constitución del 30 de diciembre de 1999, y en el caso de la ciudadanía, además se refrenda por la Ley Orgánica de Consejos Comunales (2009), por ejemplo, y en el caso de la FAN por la Ley Orgánica de la Fuerza Armada Nacional Bolivariana (2005) o la Ley Orgánica de Seguridad de la Nación (2002), principalmente.

Así, la FAN está presente en todos los ámbitos. En lo político, cuenta con toda una FAN que se encuentra bajo las órdenes del Presidente, y además, son muchos los oficiales que están asumiendo cargos públicos y políticos, en las gobernaciones, ministerios, alcaldías y administraciones públicas. En el social, por ejemplo, miles de soldados participaron en la construcción de carreteras y puentes, distribución de alimentos, vacunación de niños, ayuda a la alfabetización, y otros trabajos públicos. En lo económico, están contribuyendo a la implantación a la doctrina del socialismo del siglo XXI.

Además, la FAN también tienen que defender el país de toda agresión interna o externa; planificar y poner en práctica la doctrina militar bolivariana; servir al pueblo venezolano en la defensa de sus intereses; entrenar al pueblo para que colaboren en materia de defensa, así como en participar activamente en el desarrollo económico, científico y tecnológico de la nación. Por tanto, la FAN consti- tuye un instrumento esencial en la consolidación y realización del proyecto revolucionario bolivariano en Venezuela, más cuando los ámbitos de su actividad han sido ampliados considerablemente. Una transformación de la FAN que le lleva a desempeñar un papel importante y le convierte en una organización esencial para el proceso revolucionario.

En cuanto a la política de seguridad mencionar que la misma gira en torno al desarrollo integral, la guerra asimétrica y una nueva política exterior, tres conceptos que se han convertido en claves para la V República de Venezuela. Por tanto, las variables sobre las que gira la política de seguridad y defensa son: la fuerza armada, el pueblo, el petróleo, el activismo internacional y el establecimiento de alianzas con todo tipo de países. Elementos, por otra parte, que están contribuyendo a incrementar la presencia del país en la esfera internacional, y sobre todo, que han venido a modificar la política de defensa que parecía primar en otros momentos, y que va más allá de la mera visión militarista.

\section{Referencias bibliográficas}

Álvarez, Ángel (coord.) (1996). El sistema político venezolano: crisis y transformaciones, Caracas, Instituto de Estudios Políticos/Facultad de Ciencias Jurídicas y Políticas/Universidad Central de Venezuela.

Álvarez, Rosangel M. I (2004). La Fuerza Armada Nacional de Venezuela: ¿De actor social a actor político?, Las Vegas, Prepared for delivery at the 2004 Meeting of the Latin American Studies Association, October 7-9. 
Asamblea Nacional (1961). Constitución de la República de Venezuela, Gaceta No. 3.357, de 23 de enero de 1961. Imprenta Nacional, Caracas, Venezuela.

Asamblea Nacional (1999). Constitución Republicana de Bolivariana de Venezuela, Gaceta No. 36.860, del 30 de diciembre de 1999. Imprenta Nacional, Caracas, Venezuela.

Asamblea Nacional (2001). Decreto con Fuerza de Ley de Tierras y Desarrollo Agrario, Gaceta No. 1546. de 9 noviembre de 2001. Imprenta Nacional, Caracas, Venezuela.

Asamblea Nacional (2002). Ley Orgánica de Seguridad de la Nación, Gaceta No. 37.594. de 18 de diciembre de 2002. Imprenta Nacional, Caracas, Venezuela.

Asamblea Nacional (2005). Ley Orgánica de la Fuerza Armada Nacional, Gaceta No. 38.280 , de 26 de septiembre de 2005. Imprenta Nacional, Caracas, Venezuela.

Asamblea Nacional (2008). Ley Orgánica de Administración Pública, Gaceta No.5890, de 31 de septiembre de 2008. Imprenta Nacional, Caracas, Venezuela.

Asamblea Nacional (2009). Ley Orgánica de Consejos Comunales, Gaceta No. 39.335, de 28 de diciembre de 2009. Imprenta Nacional, Caracas, Venezuela.

Brewer-Carías, Allan R. (2007). Hacia la creación de un Estado socialista, centralizado y militarista en Venezuela". Universitas, No. 114, julio-diciembre, pp. 145-190.

Fernández Domingo, Jesús I. (2003). Presente y Futuro de las Relaciones CívicosMilitares en Hispanoamérica. Cua- dernos de Estrategia, No. 123, junio, pp. 161-185.

González Manrique, Luis Esteban (2007). Las Fuerzas Armadas como partido político: la nueva "geometría del poder" chavista. ARI, No. 117, noviembre.

González, David (2005a). Presidente controlará la FAN a través de comandos de operaciones y reserva. EI Nacional, mayo.

González, David (2005b). Reclamarán destrucción pública de fusiles desincorporados del parque de la FAN. EI Nacional, abril.

Jácome, Francine (2006). Venezuela frente al contexto andino y hemisférico. ¿Cambios en la doctrina de seguridad? (1999-2005). Caracas, Instituto Latinoamericano de Investigaciones Sociales.

Jácome, Francine (2007). Venezuela 2006: avances en la doctrina de seguridad y sus impactos regionales, Romero Méndez, Carlos; Otálvora, Edgar C.; Cardozo, Elsa; Jácome, Francine. Venezuela en el contexto de la seguridad regional, Caracas, Instituto Latinoamericano de Investigaciones Sociales, pp. 81-103.

Malamud, Carlos y García Encina, Carlota (2006). ¿Rearme o renovación del equipamiento militar en América Latina? Documento de Trabajo, Real Instituto Elcano, No. 31.

Manrique, Miguel (2001). Relaciones civiles militares en la Constitución Bolivariana de 1999, Hernán Castillo, Manuel Donís y Domingo Irwin (comp.), Militares y civiles, Caracas, USB/ UCAB/UPEL.

Manwaring, Max. G. (2006), El nuevo maestro del ajedrez mágico: El verdadero Hugo Chávez y la Guerra Asimétrica. Military Review, january-frebruary, pp. 17-29. 
Metz, Steven y Johnson, Douglas V. (2001). Asymmetry and U.S. Military Strategy: Definition, Background, and Strategic Concepts (Asimetría y estrategia de los militares estadounidenses: Definición, referencias y conceptos estratégicos), Madrid, Instituto de Estudios Estratégicos.

Ministerio del Poder Popular para la Planificación (2000). Plan Nacional de Desarrollo Económico y Social 2001-2007, Caracas, Venezuela.

Ramos Pismataro, Francesa y Otálvaro, Andrés Felipe (2004). Revolución Bolivariana; hacia una nueva concepción de seguridad y defensa en Venezuela, Colombia, Libro Seguridades en Construcción en América Latina, del Centro de Estudios Políticos e Internacionales, de la Universidad de Rosario Bogotá.

Rodríguez Franco, Xavier (2006). La democracia uniformada: El poder militar en Venezuela. Polis: Investigación y Análisis sociopolítico y psicosocial, Año/Vol. 2, No 1, primer semestre, pp. 245-272.

Romero Méndez, Carlos (2006). Las relaciones de seguridad entre Venezuela y los Estados Unidos: entre la diplomacia y el conflicto, Caracas, Instituto Latinoamericano de Investigaciones sociales.

Romero Méndez, Carlos (2007). Las relaciones de seguridad entre Venezuela y EEUU: la dimensión global, Romero Méndez, Carlos; Otálvora, Edgar C.; Cardozo, Elsa; Jácome, Francine. Venezuela en el contexto de la seguridad regional, Caracas, Instituto Latinoamericano de Investigaciones Sociales, pp. 9- 57.

Romero Méndez, Carlos; Otálvora, Edgar C.; Cardozo, Elsa; Jácome, Francine. (2007). Venezuela en el contexto de la seguridad regional, Caracas, Instituto Latinoamericano de Investigaciones Sociales.

Trinkunas, Harold (2001). Crafting civilian control in Argentina and Venezuela, David Pion-Berlin, ed. Civil-Military Relation in Latin America. New Analytical Perspective. The University of North Carolina Press.

Villegas, Ernesto (2006). En los conflictos ganan los que no participan, PAX, Año 1, No. 5, marzo-abril, pp. 24-25. 